\title{
Determination of Lard in Mixture of Body Fats of Mutton and Cow by Fourier Transform Infrared Spectroscopy
}

\author{
Irwandi JASwIR $^{1 *}$, Mohamed Elwathig Saeed Mirghani ${ }^{2}$, Torla Haji Hassan ${ }^{3}$ \\ and Mohd Zaki Mohd SAID ${ }^{1}$ \\ ${ }^{I}$ Department of Biotechnology, Faculty of Science, International Islamic University Malaysia \\ (Jalan Gombak, 53100 Kuala Lumpur, MALAYSIA) \\ ${ }^{2}$ Department of Food Technology, Faculty of Food Science and Biotechnology, Universiti Putra Malaysia \\ (43400 Serdang, Selangor, MALAYSIA) \\ ${ }^{3}$ Centre for Computational and Theoritical Science, Faculty of Science, International Islamic University Malaysia \\ (Jalan Gombak, 53100 Kuala Lumpur, MALAYSIA)
}

Edited by M. Yonese, Nagoya City Univ., and accepted August 6, 2003 (received for review April 30, 2003)

\begin{abstract}
Fourier transform infrared (FTIR) spectroscopy provides a simple and rapid means of monitoring lard when blended with mutton and cow body fats. The spectral bands associated with mutton, cow body fats and their lard blends were recorded, interpreted and identified by relating them to those spectroscopically representative pure mutton, cow and lard body fats as references. A qualitative approach is proposed by comparing the pure animal fat with blended ones. Partial least squares (PLS) regression was applied for quantitative determination of the percent of lard in its blend with mutton body fat (MBF) using FTIR spectral data at frequency regions $3010-3000,1220-1095$ and $968-965 \mathrm{~cm}^{-1}$. The equation $\mathrm{y}=1.151 \mathrm{x}$ - 0.1882, coefficient of determination $\left(\mathrm{R}^{2}\right)=0.9866$ with standard error (SE) of 2.01. For the blend with cow body fat (CBF) frequency regions $1419-1414$ and $968-965 \mathrm{~cm}^{-1}$ were used for qualitative and quantitative determination. PLS approach was used to create the equation $\mathrm{y}=$ $0.7239 \mathrm{x}+3.1369$ with $\mathrm{R}^{2}=0.9749$ and $\mathrm{SE}=1.86$. The PLS calibration models were crossvalidated and the standard deviation of difference (SDD) for repeatability and accuracy and $\mathrm{R}^{2}$ were computed.
\end{abstract}

Key words: CBF, FTIR spectroscopy, lard, MBF, PLS

\section{Introduction}

The Codex Alimentarius (1) specified that all edible animal fats must come from animals fit for human consumption, and stated some analytical identity standards for four products from animal sources. Lard is commonly blended in edible oil/fats product like butter and shortening (2). A number of investigations have been carried out by several research groups to develop analytical methods for detection of animal body fats in ghee or butter (3-6).
Although information has been published concerning animal fats, few analytical methods are available and most are either difficult to perform or time-consuming. DeMan (7) reported that the fatty acid composition of lard was different from cow body fat in C16:1, C18:3, C20: 0 and $\mathrm{C} 20: 1$, and from lamb body fat in $\mathrm{C} 14: 0$, $\mathrm{C} 16: 1, \mathrm{C} 18: 2$ and $\mathrm{C} 18: 1 t$. However, differences in fatty acid composition are too small to be used as indicator (8). In a few cases, methyl ester analysis by gas liquid chromatography (GLC) provides identification of vegetable oil adulteration with animal fats by measure-

\footnotetext{
${ }^{*}$ Correspondence to: Irwandi JASWIR, Department of Biotechnology, Faculty of Science, International Islamic University Malaysia, Jalan Gombak, 53100 Kuala Lumpur, MALAYSIA

E-mail: irwandi@iiu.edu.my
} 
ments of the C17:0 and C17:1 fatty acids. But it should be interpreted with care, because some vegetable oils such as Indian sesame seed oil may contain C17:0 and/or C17:1 acids (9).

Lambelet (3), Lambelet et al. (4) and Coni et al. (5) had reported on detection of animal body fat in ghee and butter using differential scanning calorimetry (DSC). Since lard contains a high percent of saturated fatty acids in the 2-position of the Triacylglycerols (TAGs) compared to other animal fats, determination of the fatty acids in the 2-position can be used to detect the presence of lard in other animal fats (10). TAG profiles by high-pressure liquid chromatography (HPLC) may indicate adulteration of lard by beef tallow depending on the fatty acids in the 2-position of the TAGs. Foreign fats can be determined in lard by Boemer number method (11) which is based on the difference between melting points of TAGs and the fatty acids, which is large in pure pork fat and small for others such as beef tallow fats. Haryati et al. (12), found that differences in TAG group composition in fats are reflected on the DSC thermograms. Guillen and Cabo (13) used the FTIR spectroscopy to characterize edible oil and lard. A recent study by Che Man and Mirghani (14) showed that the FTIR spectroscopy could be used in qualitative and quantitative ways for determining lard in its mixture with other animal fats. The use of FTIR spectroscopy in food analysis has been described by van de Voort et al. $(15,16)$ and Che Man and co-researchers $(17,18)$ who had developed FTIR spectroscopic methods for analysis of edible fats and oils. The present study was conducted to elaborate the possibility of detection of lard when mixed with mutton and cow body fats using FTIR spectroscopy.

\section{Experimental}

\section{2·1 Sample Preparation}

Adipose tissues from various parts of slaughtered pig (lard), cow, and mutton body fats (CBF, MBF) were obtained from a local market. The tissues were cut into small pieces, mixed, melted at $90-100^{\circ} \mathrm{C},(19)$ and strained through a triple-fold muslin cloth. The melted fat was centrifuged at $3000 \mathrm{rpm}$ (Kubota model 2010, Tokyo, Japan) for 20 minutes. The fat layer was decanted into a test tube containing anhydrous sodium sulfate $\left(\mathrm{Na}_{2} \mathrm{SO}_{4}\right)$, shaken well and centrifuged again, then decanted through a Whatman filter paper containing anhydrous $\mathrm{Na}_{2} \mathrm{SO}_{4}$. The filtered sample was directly analyzed or kept tightly closed under a nitrogen blanket in the refrigerator.

Lard was mixed with each of other melted animal fat ( $\mathrm{CBF}$ and $\mathrm{MBF}$ ) by weight to cover the range of 0 $25 \%$ lard. The pure animal body fats and the mixed samples were analyzed by means of FTIR spectroscopy.

\subsection{Instrumentation/Spectral Acquisition}

After vigorous shaking for each sample using an Autovortex Mixture SAI (Stuart Scientific, redhill, United Kingdom), a few drops were sandwiched between clean and dry sodium chloride $(\mathrm{NaCl})$ windows. A polytetrafluoroethylene (PTFE) spacer was placed between the windows to give a fixed path-length of $0.1 \mathrm{~mm}$. Cells were fitted in the sample holder in the FTIR spectrophotometer and scanning was carried out for each sample. $\mathrm{NaCl}$ windows were rinsed at least three times with pure acetone then dried. Scanning of the samples was carried out using a Perkin-Elmer 1650 series FTIR spectrophotometer (Perkin-Elmer Corporation, Norwalk, CT) equipped with a deuterated triglycine sulfate (DTGS) detector connected to a Perkin-Elmer model 7300 professional computer. Infrared data system (IRDM) software was used during FTIR data collection. FTIR data were collected from 80 scans at resolution of $4 \mathrm{~cm}^{-1}$ and strong apodization through the region 4000 to $600 \mathrm{~cm}^{-1}$. All spectra were ratioed against background air spectrum and they were recorded as absorbance values at each data point.

Windows-based software program Spectrum Lite version 1.4 (Perkin-Elmer) was used to obtain the frequency of each band using the "label peaks" command of the software or using the vertical cursor by moving it to find the frequency at the maximum absorbance for the selected band. A PLS statistical approach was developed for mathematical treatments of FTIR data. The assessment of accuracy was based on the smallest standard error (SE) and the highest coefficient of determination $\left(\mathrm{R}^{2}\right)(20)$. The "leave-one-out" cross-validation technique was used to validate calibration models, and the accuracy of each model was assessed based on standard error of prediction (SEP) and $\mathrm{R}^{2}$. Further evaluation was by comparing the mean difference and standard deviation of differences (SDD) for repeatability and accuracy between the predicted FTIR data and the actual lard content in the samples of animal fat blends. 


\section{Results and Discussion}

\section{3·1 Mutton Body Fat (MBF)}

Figure 1 shows the FTIR spectra of both mutton body fat (MBF) and lard. The spectra illustrate the dominant spectral features associated with each of them as for general fats and oils (21), $\mathrm{CH}$ stretching absorption in the frequency region $3050-2800 \mathrm{~cm}^{-1}$, the carbonyl absorption of the triacylglycerol ester linkage at $1746-1744 \mathrm{~cm}^{-1}$ and the bands associated with the fingerprint region $1500-1000 \mathrm{~cm}^{-1}$. The differences observed from raw spectra between MBF and lard appears in three frequency regions, 3010 - 3000, 1120 1095 , and $968-966 \mathrm{~cm}^{-1}$. These three regions are illustrated in Fig. 1 as a, b and c, respectively.

The difference between spectra of MBF and lard appear in the frequency region $3010-3000 \mathrm{~cm}^{-1}$ (a) as shown in Fig. 1 and 2, where lard spectrum has a sharp band at higher frequency $\left(3009 \mathrm{~cm}^{-1}\right)$ than MBF which has a shoulder peak at low frequency $\left(3001 \mathrm{~cm}^{-1}\right)$. Spectra 1\%L - 25\%L in Fig. 2 represents the blends of $1-25 \%$ lard with MBF. Bands in this region (a) are due to the cis double bond stretching vibration (13); accordingly, fats with high proportion of linolenic or linoleic acyl groups show higher frequency for this

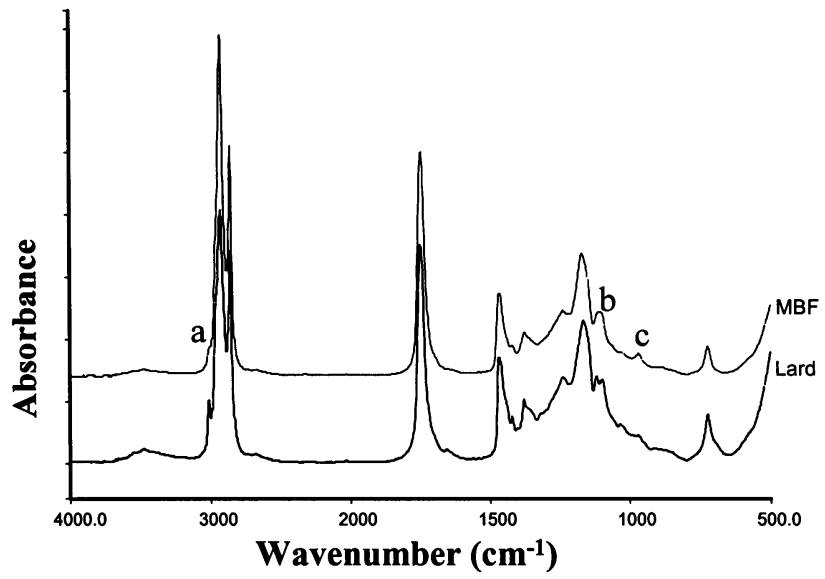

Fig. 1 FTIR Spectra of (Lard) Pure Lard and (MBF) Pure MBF. The labeled peaks are absorption bands that are significant in the determination.

band than fats with high proportion of oleic acyl groups. This result agrees with the fatty acid composition for lard and MBF (8), which is high in oleic and lower in linoleic and linolenic compared to lard. At the FTIR frequency region $1120-1095 \mathrm{~cm}^{-1}$ lard showed overlap of two peaks having maximum absorption at 1119 and $1100 \mathrm{~cm}^{-1}$, (b) in Fig. 1. This has been found to be related, in an inverse way, to the proportion of sat-

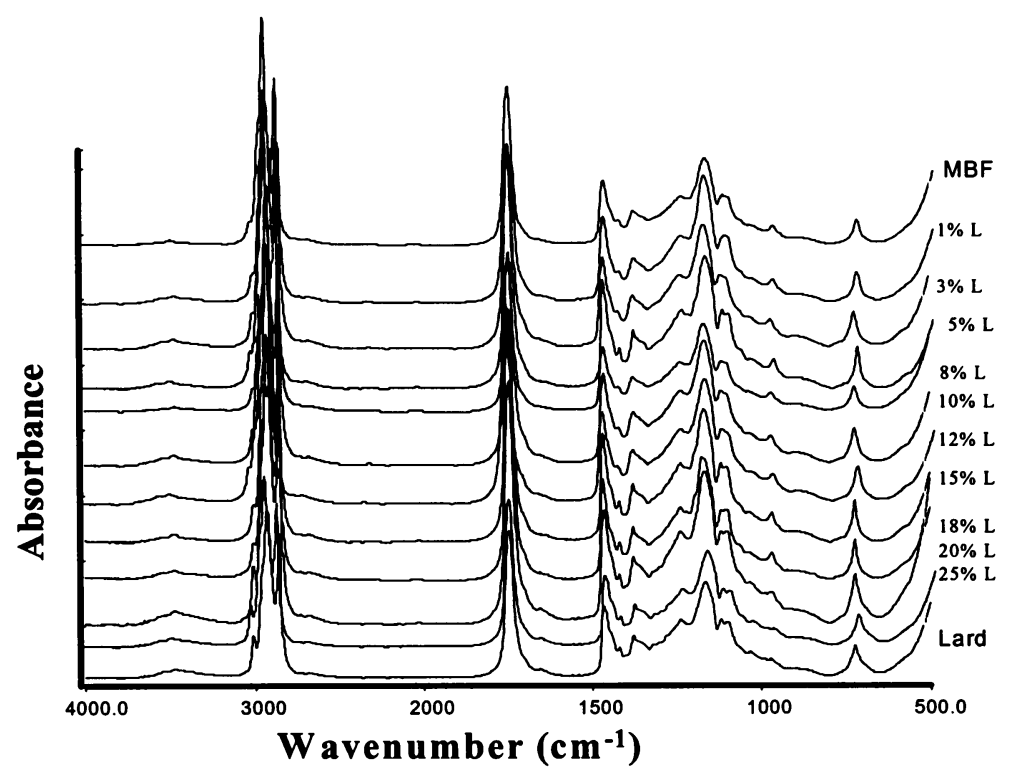

Fig. 2 FTIR Spectra of MBF, (1, 3, 5, 8, 10, 12, 15, 18, 20, and 25\% Lard) and Pure Lard Shows Changes in Frequency and Absorbance within the Regions 3010 - 3000, 1120 - 1095, and $968-966 \mathrm{~cm}^{-1}$ (a, b, and c in Fig. 1) due to \% of Lard in the Blend with MBF. 
urated acyl groups and oleic acyl groups, respectively (21). From the above results it could be concluded that both lard and MBF contain saturated and oleic acyl groups in their structures in some sort of variation. The MBF spectrum showed a clear band at $966-967 \mathrm{~cm}^{-1}$ which is known to be due to the $\mathrm{C}=\mathrm{C}-\mathrm{H}$ bending vibration of trans double bonds $(22,23)$, while lard spectrum has no clear band (c) in Fig. 1. The band at the same region $975-965 \mathrm{~cm}^{-1}$ in the IR spectrum is the basis of the AOCS official method for determination of trans groups (24).

A quantitative assessment is proposed using the frequency regions $(3010$ - 3000, 1120 - 1095, and 968 $965 \mathrm{~cm}^{-1}$ ) and PLS statistical to assess the variation in frequency and absorbance as a function of the ratio of blending of lard with MBF, which is shown in Fig. 3 and the equation: $\mathrm{Y}=1.151 \mathrm{x}-0.1882$ with coefficient of determination $\left(\mathrm{R}^{2}\right)$ of 0.9866 and SE of 2.01. Data was cross-validated resulting in $\mathrm{R}^{2}$ of 0.9769 (Fig. 4) and standard error of prediction (SEP) of 2.23

\section{$3 \cdot 2$ Cow Body Fat (CBF)}

Figure 5 shows the spectra of both lard and cow body fat CBF. In the frequency region $3008-3003 \mathrm{~cm}^{-1}$ (a) the CBF has small or shoulder peak while the lard peak is clear and sharp. The second difference is band at frequency of $1418 \mathrm{~cm}^{-1}$ (b), which can be attributed to rocking vibrations of $\mathrm{CH}$ bonds of $c i s$-disubstituted olefins (13). The third difference is for the presence of $\mathrm{C}=\mathrm{CH}$ - trans stretching at frequency $966 \mathrm{~cm}^{-1}$ (c),

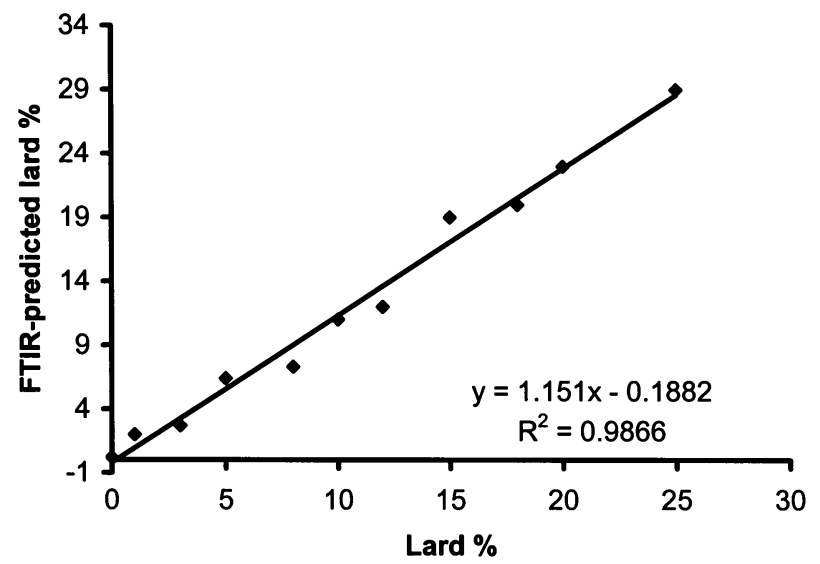

Fig. 3 A Plot of Concentration of Lard (\%) in the Blend with MBF versus FTIR-Predicted Concentration of Lard (\%) Using PLS and Spectral Data at Frequency Regions 3010-3000, 1120-1095, and $968-965 \mathrm{~cm}^{-1}$ for Calibration. where there is a sharp peak for the CBF spectrum while no clear one for the lard spectrum.

The bands at $3008-3003 \mathrm{~cm}^{-1}$ could be used for qualitative analysis to differentiate between pure lard and pure $\mathrm{CBF}$ as it shows a sharp peak for lard spectrum while small or a shoulder peak for CBF spectrum. The frequency region $1419-1414 \mathrm{~cm}^{-1}$ could be used for qualitative determination of lard when blended with $\mathrm{CBF}$ covering the range of $00-25 \%(\mathrm{w} / \mathrm{w})$ of lard in CBF. Qualitatively it is easy to differentiate between the FTIR spectra of lard and CBF in Fig. 5, because the last one showed a clear band at frequency $966 \mathrm{~cm}^{-1}$ while lard shows no peak at the same frequency due to the content of trans fatty acid in CBF (8). In Fig. 6 when the ratio of lard increases, the absorbance at $966 \mathrm{~cm}^{-1}$ decreases showing the lower content of trans fatty acids in lard than CBF. This is in agreement with the study by Guillen and Cabo (13) that didn't mention any peak at frequency $966 \mathrm{~cm}^{-1}$ for lard spectrum. PLS statistical approach was used for quantitative determination of lard when mixed with CBF using the spectral data at the regions $1419-1414$ and $968-965 \mathrm{~cm}^{-1}$. The equation created is $\mathrm{Y}=0.7239 \mathrm{x}+3.1369$ with $\mathrm{R}^{2}$ and $\mathrm{SE}$ of 0.9749 and 1.86, respectively (Fig. 7). Figure 8 shows the cross-validation results of $\mathrm{R}^{2}=0.96$ and SEP of 2.30

Table 1 shows the statistical results calculated form the cross validation as mean difference (MD) and standard deviations of difference (SDD) for repeatability and accuracy for the determination of both lard blends with

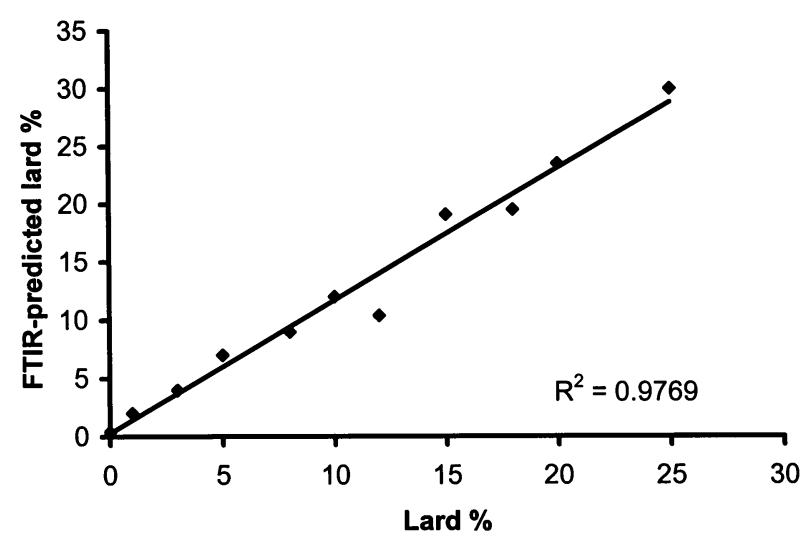

Fig. 4 A Plot of Concentration of Lard (\%) in the Blend with MBF versus FTIR-Predicted Concentration of Lard (\%) Using PLS and Spectral Data at Frequency Regions 3010-3000, 1120-1095, and 968-965 $\mathrm{cm}^{-1}$ for Cross-Validation. 


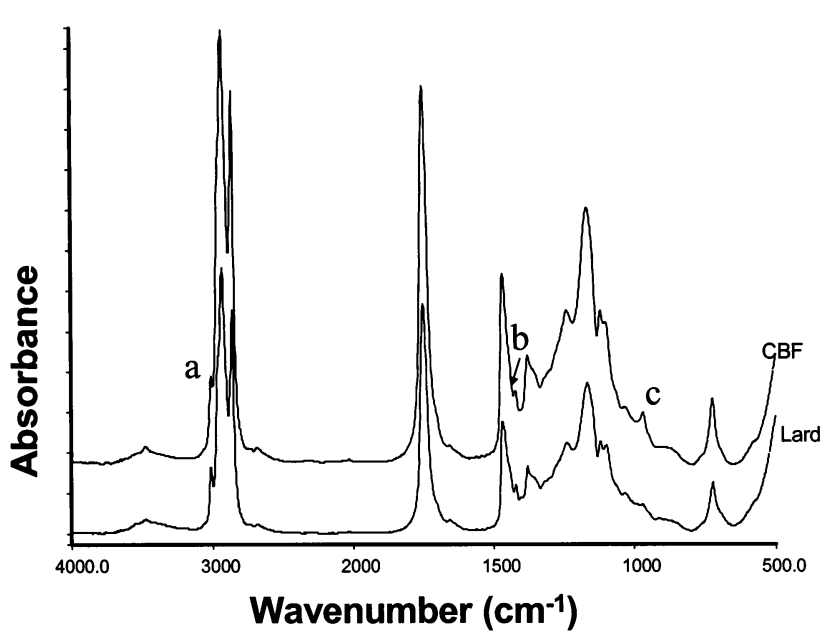

Fig. 5 FTIR Spectra of (Lard) Pure Lard and (CBF) Pure CBF. The labeled peaks are absorption bands that are significant in the determination.

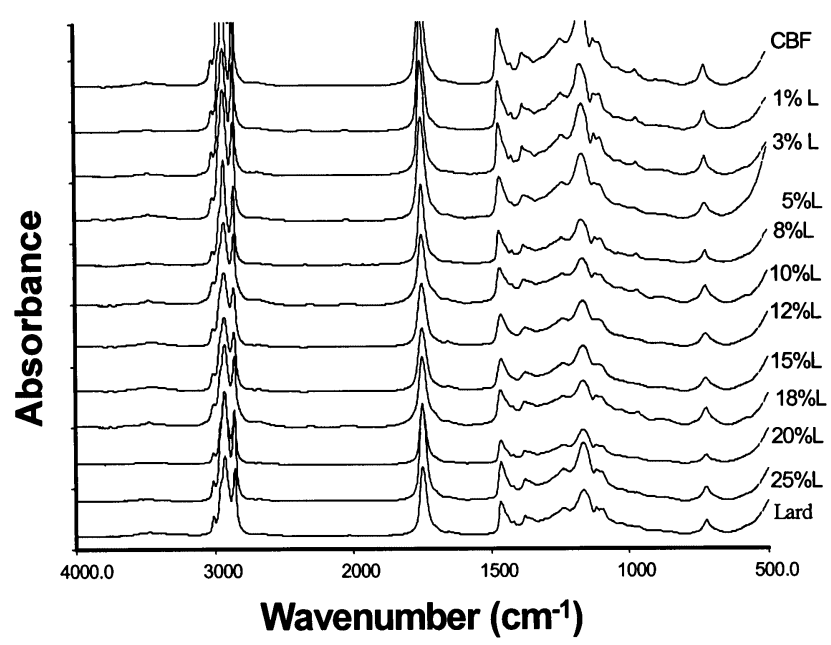

Fig. 6 FTIR Spectra of CBF, (1, 3, 5, 8, 10, 12, 15, 18, 20, and $25 \%$ Lard) and Pure Lard Showed Changes in the Absorbance at Frequency Regions 1419 - 1416 and 968 - 966 (b and c in Fig. 3).

\section{$\mathrm{CBF}$ and $\mathrm{MBF}$.}

The use of Fourier Transform Infrared (FTIR) spectroscopy in this study offers a rapid, consistent and reproducible analytical technique that could be used as a quality measure for animal fats in their neat form. Further benefits of using FTIR spectroscopic method is that the tedious time- and chemical - consuming stand-

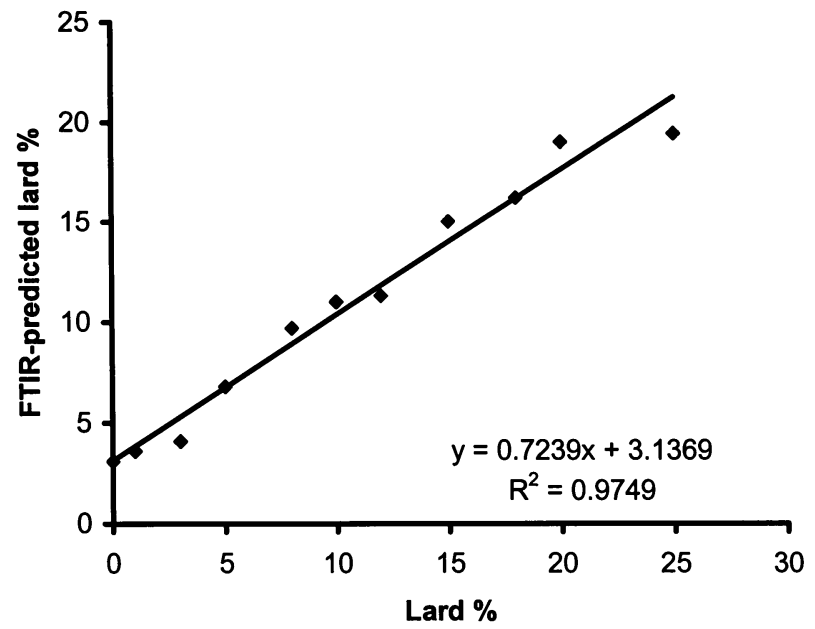

Fig. 7 A Plot of Concentration of Lard (\%) in the Blend with CBF versus FTIR-Predicted Concentration of Lard (\%) Using PLS and Spectral Data at Frequency Regions 1419-1416, and 968-965 $\mathrm{cm}^{-1}$ for Calibration.

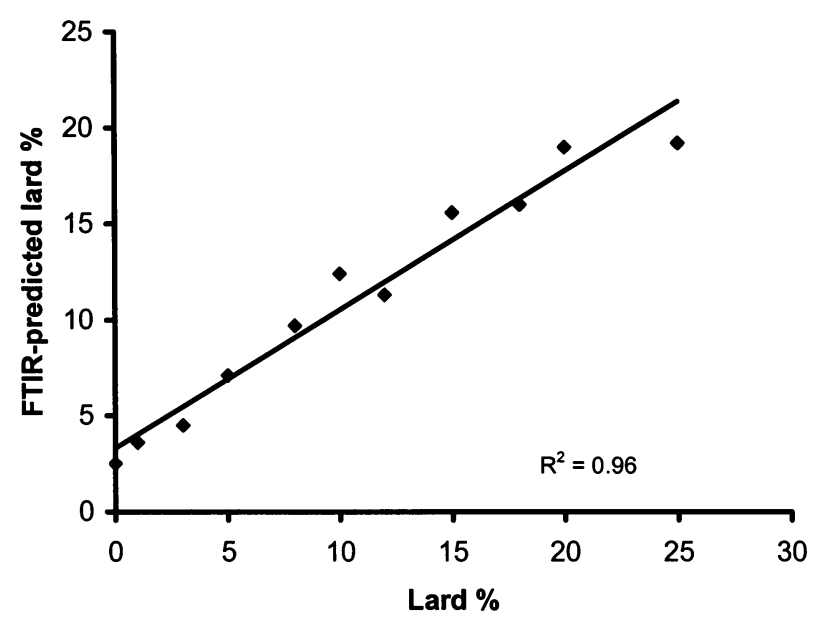

Fig. 8 A Plot of Concentration of Lard (\%) in the Blend with CBF versus FTIR-Predicted Concentration of Lard (\%) Using PLS and Spectral Data at Frequency Regions 1419-14165, and 968-965 $\mathrm{cm}^{-1}$ for Cross-Validation.

ard chemical methods can be avoided. The study could be extended by using specific sampling regarding - for example - other animals fat, milk fats and vegetable oils. Once the database is established and the model developed, each individual FTIR analysis can be achieved in about 3 - 5 minutes. 
Table 1 Repeatability and Accuracy of FTIR Predictions of Lard Content in MBF and CBF Obtained by Cross Validation ${ }^{\mathrm{a}}$.

\begin{tabular}{lcrcr}
\hline & \multicolumn{2}{c}{ MBF } & \multicolumn{2}{c}{ CBF } \\
\cline { 2 - 5 } Statistics & Actual & FTIR & Actual & FTIR \\
\hline MDr & 4.06 & 3.72 & 4.31 & 3.29 \\
SDDr & - & -1.24 & - & -2.09 \\
MDa & \multicolumn{2}{c}{2.49} & \multicolumn{2}{c}{2.37} \\
SDDa & \multicolumn{2}{c}{1.18} & \multicolumn{2}{c}{1.14} \\
\hline
\end{tabular}

${ }^{a}$ FTIR, Fourier transform infrared; CBF, cow body fat; MBF, mutton body fat; MD, mean difference; SDD, standard deviation of difference; r, repeatability; a, accuracy.

\section{Acknowledgments}

This study was funded by the Research Centre of the International Islamic University Malaysia.

\section{References}

1. Codex Alimentarius, Fats Oils and Related Products, Food and Agriculture Organization of the United Nations, World Health Organization, Vol. 8, part 3, Rome, (1993).

2. N.O.V. SONNTAG, Bailey's Industrial Oil and Fat Products (D. SWERN, ed.), 4th edn., Vol. 2, Awiley-Interscience Publications, pp. 159-161 (1982).

3. P. LAMBELET, Detection of Pig and Buffalo Body Fat in Cow and Buffalo Ghee by Differenctial Scanning Calorimetry, J. Am. Oil Chem. Soc., Vol. 60, 1005-1008 (1983).

4. P. LAMBELET, O.P. SINGHAL and N.C. GANGULI, Detection of Goat Body Fat in Ghee by Differential Thermal Analysis, J. Am. Oil Chem. Soc., Vol. 57, 364-366 (1980).

5. E. CONI, M.D. PASQUALE, P. COPPOLELLI and A. BOCCA, Detection of Animal Fats in Butter by Differential Scanning Calorimetry: A Pilot Study, J. Am. Oil Chem. Soc., Vol. 71, 807810 (1994).

6. E.W. HAMMOND and J.W. IRWIN, HPLC in Food Analysis (R. MACRAE, ed.), 2nd edn., Academic Press, London, pp. 95132 (1988).

7. J.M. DeMAN, Functionality Requirements of Fats and Oils for Food Applications, MOSTA Tech-In, Recent Advances in the Sciences of Oils and Fats, Malaysian Oil Scientists' and Technologists' Association, Petaling Jaya, Selangor D.E. Malaysia (1999).

8. M. ENSER, Development in Oils and Fats (R.J. HAMILTON, ed.), Blakie Academic and Professional, pp. 1-31 (1995).

9. H.P. KAUFMANN and G. MANKED, Bailey's Industrial Oil and Fat Products (D. SWERN, ed.), Vol. 2, 4th edn., Wiley Interscience Publications, p. 482 (1982).

10. C. PAQUOT, Standard Methods for Analysis of Oils, Fats and Drivatives, IUPAC Commission on Oils, Fats and Drivatives, 6th edn., Pergamon, N.Y., Method 2.210 (1979).

11. AOCS, Official and Tentative Methods and Recommended Prac- tices of the American Oil Chemists' Society (D. FIRESTONE, ed.), 4th edn., American Oil Chemists' Society, Champaign, Illinois, Method Cb 5-40 (1993).

12. T. HARYATI, Y.B. Che MAN, H.M. GHAZALI, A. ASBI and L. BUANA, Determination of Iodine Value of Palm Oil Based on Triglyceride Composition, J. Am. Oil Chem. Soc., Vol. 75, 793-799 (1998).

13. M.D. GUILLEN and N. CABO, Characterization of Edible Oils and Lard by Fourier Transform Infrared Spectroscopy, Relationship between Composition and Frequency of Concrete Bands in the Fingerprint Region, J. Am. Oil Chem. Soc., Vol. 74, 12811286 (1997).

14. Y.B. Che MAN and M.E.S. MIRGHANI, Detection of Lard Mixed with Body Fats of Chicken, Lamb, and Cow by Fourier Transform Infrared Spectroscopy, J. Am. Oil Chem. Soc., Vol. 78, 753-761 (2001).

15. F.R. van de VOORT, A.A. ISMAIL, J. SEDMAN, J. DUBOIS and T. NICODEMO, The Determination of Peroxide Value by Fourier Transform Infrared Spectroscopy, J. Am. Oil Chem. Soc., Vol. 71, 921-926 (1994).

16. F.R. van de VOORT, A.A. ISMAIL and J. SEDMAN, A Rapid Automated Method for Determination of cis and trans Content of Fats and Oils by Fourier Transform Infrared Spectroscopy, $J$. Am. Oil Chem. Soc., Vol. 72, 873-880 (1995).

17. Y.B. Che MAN and M.E.S. MIRGHANI, Rapid Method for Determining Moisture Content in Crude Palm Oil by Fourier Transform Infrared Spectroscopy, J. Am. Oil Chem. Soc., Vol. 77, 631-637 (2000).

18. Y.B. Che MAN, G. SETIOWATY and F.R. van de VOORT, Determination of Iodine Value of Palm Oil by Fourier Transform Infrared Spectroscopy, J. Am. Oil Chem. Soc., Vol. 76, 693-700 (1999).

19. G. HOFFMANN, The Chemistry and Technology of Edible Oils and Fats and Their High Fat Products, Academic Press, p. 127 (1989).

20. J. DUBOIS, F.R. van de VOORT, J. SEDMAN, A.A. ISMAIL and H.R. RAWASWAMY, Quantitative Fourier Transform Infrared Analysis for Anisidine Value and Aldehyde in Thermally Stressed Oils, J. Am. Oil Chem. Soc., Vol. 73, 787-794 (1996).

21. D. FIRESTONE and A. SHEPPARD, Determination of trans Fatty Acids, in Advances in Lipid Methodology (W.W. CHRISTIE, ed.), The Oily Press, Alloway, Scotland, pp. 273322 (1992).

22. D. FIRESTONE and P. LaBOULIERE, Determination of Isolated trans Isomers by Infrared Spectrophotometry, J. Am. Oil Chem. Soc., Vol. 48, 437-443 (1965).

23. AOCS, Official Methods and Recommended Practices of the American Oil Chemists' Society (D. FIRESTONE, ed.), 4th edn., American Oil Chemists' Society, Champaign, Illinois, 1995, Method Cd 14-95 (1993).

24. J. SEDMAN, F.R. van de VOORT and A.A ISMAIL, Upgrading the AOCS Infrared trans Method for Analysis of Neat Fats and Oils by Fourier Transform Infrared Spectroscopy, J. Am. Oil Chem. Soc., Vol. 74, 907-913 (1997). 